\section{Bglll RFLP for the human fumarylacetoacetate hydrolase (FAH) gene}

Sylvie I.Demers and Robert M.Tanguay*

Ontogénèse et Génétique Moléculaire, Centre de

Recherches du CHUL, 2705 Boulevard Laurier, Ste-Foy,

Québec G1V 4G2, Canada

Source and Description of Clone: The probe phHAC is a 480 bp PstI/EcoRI fragment from the $3^{\prime}$ end of phHA2, a $1.5 \mathrm{~kb}$ human fumarylacetoacetate hydrolase cDNA clone containing all the FAH coding sequence (1).

Polymorphism: BglII detects a three-allele polymorphism with variant fragments of $16.4 \mathrm{~kb}$ (D1), $12.7 \mathrm{~kb}$ (D2) and $6.6 \mathrm{~kb}$ (D3). One constant band is present at $3.0 \mathrm{~kb}$.

Frequency: Estimated from 35 unrelated (at least at the second degree) French-Canadian individuals.

D1: 0.25

D2: 0.38

D3: 0.37

Heterozygosity for BglII alleles is $\mathbf{0 . 6 6 .}$

Not Polymorphic For: BamHI, EcoRV, HaeIII, HindIII, HpaII, and Pall studied in 15 unrelated individuals. The DNA source is blood lymphocytes.

Chromosomal Localization: The human FAH gene has been localized to $15 \mathrm{q} 23-25$ (1).

Mendelian Inheritance: Codominant segregation demonstrated in eighteen families (64 individuals).

Probe Availability: Available for collaboration. Contact Dr. R.M.Tanguay.

Clinical Relevance: Fumarylacetoacetate hydrolase is the enzyme deficient in type 1 hereditary tyrosinemia (2).

Acknowledgements: Supported by the MRC of Canada (Grant MA-11081) and the FRSQ (Studentship).

References: 1)Phaneuf,D. et al. (1991) Am. J. Hum. Genet. 48, 525-535. 2)Tanguay,R.M. et al. (1990) Am. J. Hum. Genet. 47, 308-316.

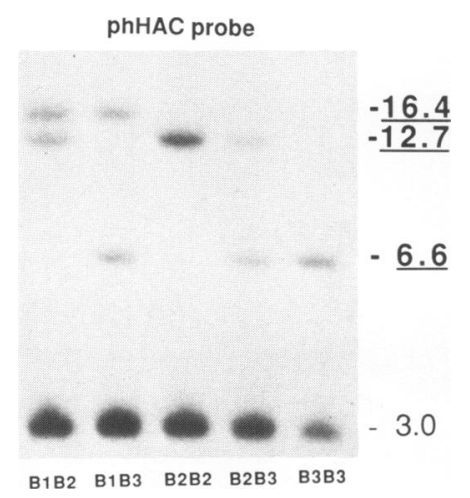

* To whom correspondence should be addressed

\section{Kpnl and Rsal RFLPs for the human fumarylacetoacetate hydrolase $(F A H)$ gene}

Sylvie I.Demers and Robert M.Tanguay

Ontogénèse et Génétique Moléculaire, Centre de Recherches du CHUL, 2705 Boulevard Laurier, Ste-Foy, Québec G1V 4G2, Canada

Source and Description of Clone: phHA2 is a $1.5 \mathrm{~kb}$ human fumarylacetoacetate hydrolase cDNA clone isolated from a human liver $\lambda$ gt11 cDNA library and subcloned at the EcoRI site of plasmid pGEM-7Zf. The cDNA insert (EMBL accession number M55150) contains all the FAH coding sequence (1).

Polymorphism: KpnI reveals 2 two-allele polymorphisms (Ba and $\mathrm{Bb})$ : $15.9 \mathrm{~kb}$ (B1), $5.5 \mathrm{~kb}$ (B2) and $3.7 \mathrm{~kb}$ (B1), $2.5 \mathrm{~kb}$ (B2). Two constant bands of $10.7 \mathrm{~kb}$ and $6.6 \mathrm{~kb}$ are also observed. A $10.4 \mathrm{~kb}$ allelic DNA fragment which is masked by the superposed $10.7 \mathrm{~kb}$ constant band can be visualized with a 414 bp EcoRI/SphI subfragment (phHAA) from the 5' end of phHA2.

RsaI recognizes a two-allele polymorphism: $2.0 \mathrm{~kb}(\mathrm{C} 1)$ and $0.3 \mathrm{~kb}(\mathrm{C} 2)$. Six invariable bands of $2.3 \mathrm{~kb}, 1.8 \mathrm{~kb}, 1.6 \mathrm{~kb}, 1.3$ $\mathrm{kb}, 1.0 \mathrm{~kb}$ and $0.7 \mathrm{~kb}$ are detected.

Frequency: Studied in 36 unrelated French-Canadians.

$\begin{array}{llll}\text { Set } \mathrm{Ba} & \text { Allele } & \text { B1: } 0.62 & \text { C1: } 0.62\end{array}$

$\begin{array}{lll} & & \text { B2: } 0.38 \\ \text { Set } \mathrm{Bb} & \text { Allele } & \mathrm{B} 1: 0.97 \\ & & \mathrm{~B} 2: 0.03\end{array}$

Heterozygosities for $\mathrm{Ba}$ and $\mathrm{Ca}$ allele sets are 0.47 and 0.06 for $\mathrm{Bb}$ allele set. Observed frequencies of heterozygotes and homozygotes fit Hardy-Weinberg equilibrium.

Not Polymorphic For: BamHI, EcoRV, HaeIII, HindIII, HpaII, and Pall in a panel of 15 unrelated individuals. The DNA source is blood lymphocytes.

Chromosomal Localization: The human FAH gene has been mapped to 15q23-25 (1).

Mendelian Inheritance: Confirmed in seventeen families (61 individuals) for the $\mathrm{Ba} 1 / \mathrm{Ba} 2$ alleles, in two families (6 ind.) for $\mathrm{Bb} 1 / \mathrm{Bb} 2$ and in six families (20 ind.) for the RsaI alleles.

Probe Availability: Available for collaboration. Contact Dr. R.M.Tanguay.

Clinical Relevance: Fumarylacetoacetate hydrolase is the enzyme deficient in type 1 hereditary tyrosinemia (2).

Acknowledgements: Supported by the MRC Canada (Grants PG-35 and MA-11081) and by a studentship from the FRSQ. References: 1)Phaneuf,D. et al. (1991) Am. J. Hum. Genet. 48, 525-535. 2)Tanguay,R.M. et al. (1990) Am. J. Hum. Genet. 47, 308-316.

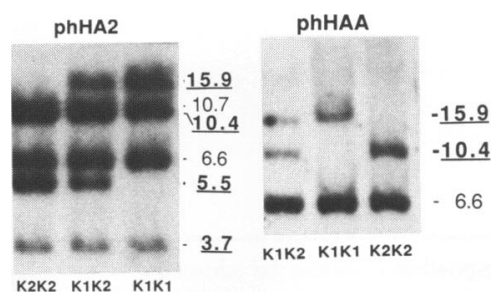

